\title{
An effective sensor for tool wear monitoring in face milling: Acoustic emission
}

\author{
M T MATHEW ${ }^{1 *}$, P SRINIVASA PAI $^{2}$ and L A ROCHA ${ }^{1,3}$ \\ ${ }^{1}$ Centre for Materials and Mechanical Technologies (CT2M), Azurém, \\ 4800058 Guimarães, Portugal \\ ${ }^{2}$ Department of Mechanical Engineering, NMAM Institute of Technology, \\ Nitte 574110 \\ ${ }^{3}$ Universidade do Minho, Department Engineering Mecânica, Azurém, \\ 4800058 Guimarães, Portugal \\ e-mail: mathew@dem.uminho.pt
}

\begin{abstract}
Acoustic Emission (AE) has been widely used for monitoring manufacturing processes particularly those involving metal cutting. Monitoring the condition of the cutting tool in the machining process is very important since tool condition will affect the part size, quality and an unexpected tool failure may damage the tool, work-piece and sometimes the machine tool itself. AE can be effectively used for tool condition monitoring applications because the emissions from process changes like tool wear, chip formation i.e. plastic deformation, etc. can be directly related to the mechanics of the process. Also AE can very effectively respond to changes like tool fracture, tool chipping, etc. when compared to cutting force and since the frequency range is much higher than that of machine vibrations and environmental noises, a relatively uncontaminated signal can be obtained.

AE signal analysis was applied for sensing tool wear in face milling operations. Cutting tests were carried out on a vertical milling machine. Tests were carried out for a given cutting condition, using single insert, two inserts (adjacent and opposite) and three inserts in the cutter. AE signal parameters like ring down count and rms voltage were measured and were correlated with flank wear values (VB max). The results of this investigation indicate that $\mathrm{AE}$ can be effectively used for monitoring tool wear in face milling operations.
\end{abstract}

Keywords. Tool wear monitoring; acoustic emission; inserts.

\section{Introduction}

Monitoring of tool wear is an important requirement for realizing automated manufacturing. Tool wear is a very complex phenomenon which can lead to machine down time, product rejects and can also cause problems to personnel (Dimla et al 1997). In-process sensing of

*For correspondence 


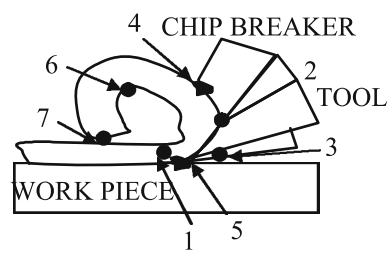

CASE OF CONTINOUS CHIP FORMATION

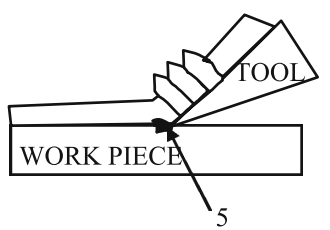

CASE OF DISCONTINOUS CHIP FORMATION

Numbers are showing the possible sources of $A E$

Figure 1. Sources of AE in metal cutting.

tool wear is an important function for the adaptive control of machine tools. Tool condition monitoring is a critical area for the success of any machining process where the tool is in constant or intermittent contact with the work-piece and can be subjected to either continuous wear or catastrophic failure like chipping, fracture, etc. This problem is currently being addressed by many metal cutting researchers through the development of improved sensors. Sensors function to collect information for the evaluation of the condition of the tool. Various types of sensors are available which could be effectively used for tool wear monitoring and include acoustic emission (AE), vibration, temperature, force, etc. (Pai \& Rao 1998).

Research has shown that AE, which refers to stress waves generated by the sudden release of energy in deforming or fracturing materials, could be successfully used for detecting tool wear and fracture in single point turning operations. Further studies have also indicated that the use of $\mathrm{AE}$ for monitoring the condition of the tool in multi-point cutting tool operations like drilling and milling.

During metal cutting, AE generated is mainly from plastic deformation and fracture. Other sources of AE signals are shown in figure 1. The analysis of acoustic emission signals generated during machining has been proposed as a technique for studying both the fundamentals of the cutting process and tool wear, and also as a methodology for detecting tool wear and failure on-line (Lister \& Barrow 1986).

The goal of present investigation is to detect AE signals from insert-milling operation and to correlate the various signal parameters with the status of the tool.

\section{Experimental details}

The schematic diagram of the experimental set-up used for the investigation is shown in figure 2. Tests were carried out on a Bharat Fritz Werner Vertical milling machine. The workpiece material was En-8 (medium carbon steel) with dimension $63 \times 140 \times 63 \mathrm{~mm}$ and tests were carried out with single, two and three inserts (uncoated carbide insert, SEKN 1203 AFN TTMS, WIDIA Hard Metal Grade) in the cutter. Table 1 explains the experimental conditions employed in the test. The various combinations of cutting speed and feed were chosen such that the tool was subjected to progressive wear. However, results for only three experiments are reported here. The depth of cut was kept constant. The experiments were carried out beyond the specified width of flank wear land (VB max), till the insert failed. Also for the selected cutting conditions, crater wear was not formed on the tool and hence it has not been considered in the investigation.

The AE signals were sensed using a AC 7502425 piezoelectric transducer, mounted on the machine vice as shown in the figure 2 . The signals were suitably amplified using a preamplifier 


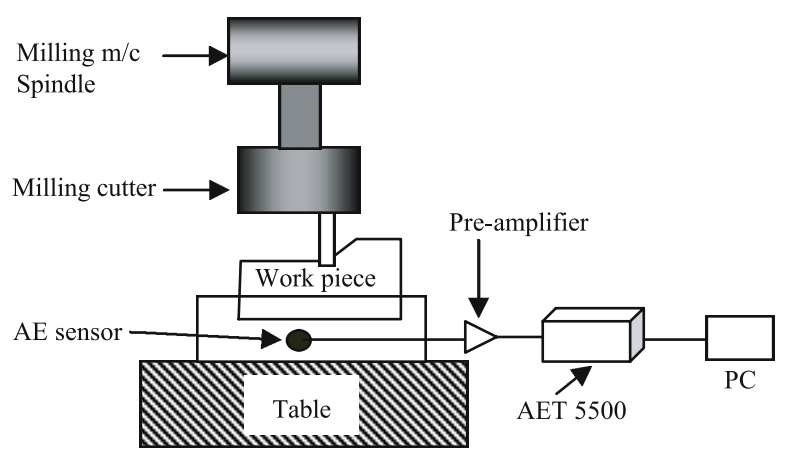

Figure 2. Experimental set-up.

(60 dB gain) and filtered using a wide band filter $(30 \mathrm{KHz}-2 \mathrm{MHz})$ and was recorded using AET 5500 AE Signal Analyzer. The necessary threshold settings were made and the system software was used to collect the data, so that it could be analysed. At the end of every two cutting passes, the tool(s) was removed from the cutter and the width of the flank wear land was measured using a Tool Maker's Microscope. In case of experiments involving two and three inserts, for the sake of analysis and investigation, the average flank wear values have been considered. The critical wear value for the experiments in this investigation has been taken as $0.4 \mathrm{~mm}$.

\section{Results and discussion}

The analysis of the experimental results is carried out as follows: initially the results obtained with single insert in the cutter is discussed, then a comparison of the results obtained with two and three inserts in the cutter is made with that of results obtained using single insert. The observations are made based on the fact that the surface area of the work piece is less than that of the cutter diameter $(100 \mathrm{~mm})$.

\subsection{Single insert experiments}

Figure 3 shows the variation of flank wear with cutting time. The behaviour shows rapid increases initially, followed by wear progressing at a uniform rate and again wear increasing rapidly.

Table 1. Experimental conditions.

\begin{tabular}{lccccc}
\hline $\begin{array}{l}\text { Exp. } \\
\text { No }\end{array}$ & $\begin{array}{c}\text { Depth } \\
\text { of cut }\end{array}$ & $\begin{array}{c}\text { speed } \\
\mathrm{mm} / \mathrm{min}\end{array}$ & $\begin{array}{c}\text { Feed } \\
\text { mm/tooth }\end{array}$ & $\begin{array}{c}\text { Max wear } \\
(\mathrm{mm})\end{array}$ & $\begin{array}{c}\text { No. of } \\
\text { inserts }\end{array}$ \\
\hline 1 & 0.5 & 176 & 0.22 & 0.59 & $\begin{array}{c}1 \\
2 \\
\text { (adjacent } \\
\text { and } \\
\text { opposite) } \\
3\end{array}$ \\
& 0.5 & 176 & 0.11 & 0.76 & 3 \\
\hline
\end{tabular}




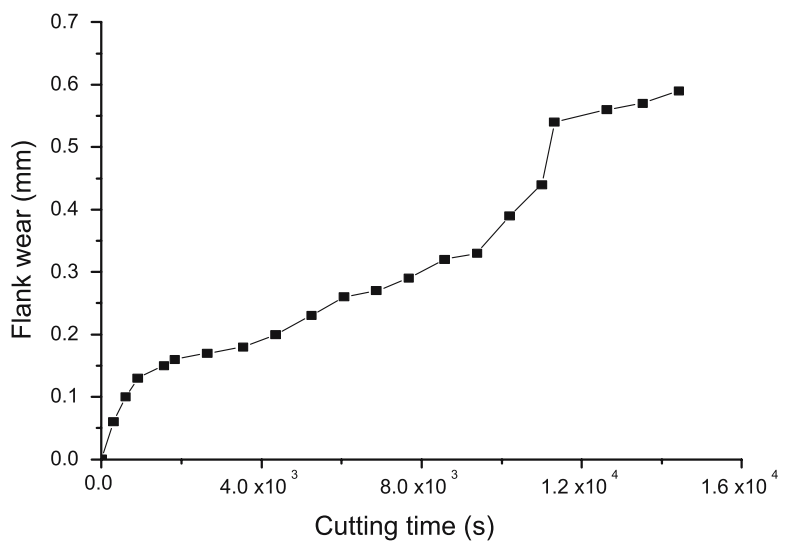

Figure 3. Variation of flank wear with time (single insert).

The variation of ring down count (RDC) and rms voltage with flank wear are shown in the figure 4. Initially, ring down count value increases rapidly and then drops down and then again increases. The initial increase is because of the micro-fracturing taking place when the insert comes in contact with the work-piece, producing more of burst emissions. Then as machining continues, there will be normal metal removal in the form of chips, which will give rise to more of continuous emissions. But as machining continues, the flank face of the insert comes in contact with the work piece surface leading to rubbing and friction, giving rise to flank wear. As cutting time increases, there will be more and more rubbing on the flank face giving rise to more of burst emissions. Also tool entry and exit generates burst emissions along with the variation of chip thickness throughout each cutting cycle. This causes an overall increase in the ring down count. Similar behaviour can be seen with respect to rms voltage. Also as the speed and feed increases, the wear increases.

\subsection{Two inserts experiments}

Figure 5 shows the variation of average flank wear with cutting time for two arrangements of inserts in the cutter, namely adjacent and opposite. The behaviour is similar to that for a

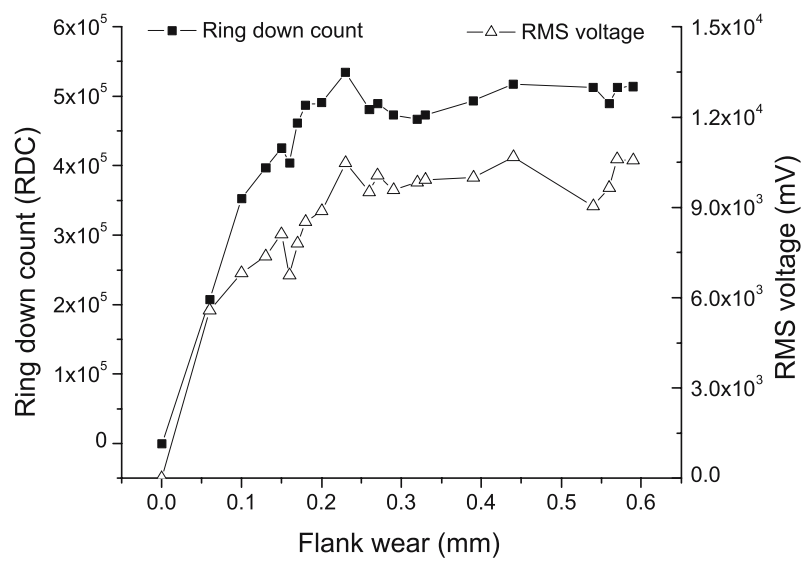

Figure 4. Evolution of Ring down count (RDC) and RMS voltage with flank wear. 


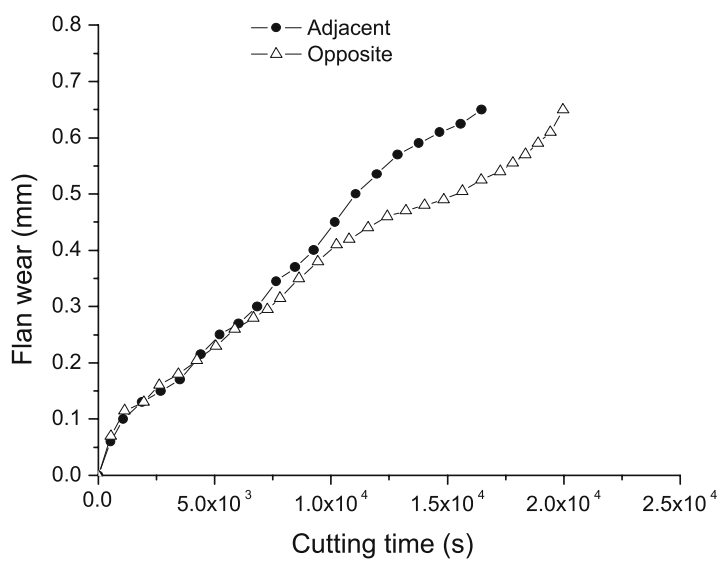

Figure 5. Variation of average flank wear with cutting time ( 2 inserts).

single insert. Since the wear undergone by both the inserts is similar in both cases, for the sake of analysis the average flank wear value has been considered.

Figures 6 and 7 show the variation of ring down count and rms voltage with average flank wear. For higher speed and feed, rms voltage is very clear in distinguishing the normal state from the abnormal state of tool wear.

\subsection{Three inserts experiments}

Figure 8 shows the variation of RDC and RMS voltage with average flank wear. RDC shows a similar behaviour to that of a single insert. However, there are fluctuations, as three inserts are cutting simultaneously, thereby affecting the AE generation. The RMS voltage shows a decreasing trend with an increase in flank wear.

\subsection{Comparisons}

The values of the AE parameters for different cutting conditions and different number of inserts in the cutter are different, higher in two and three insert experiments, when compared to single insert experiment.

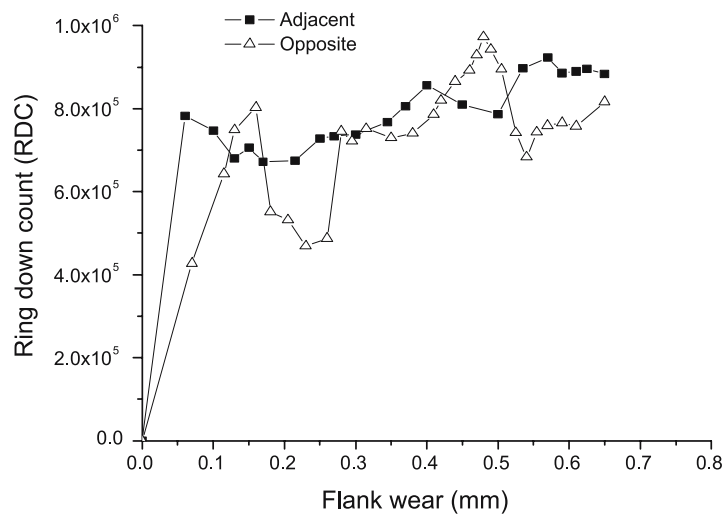

Figure 6. Evolution of ring down count (RDC) with flank wear (2 inserts). 


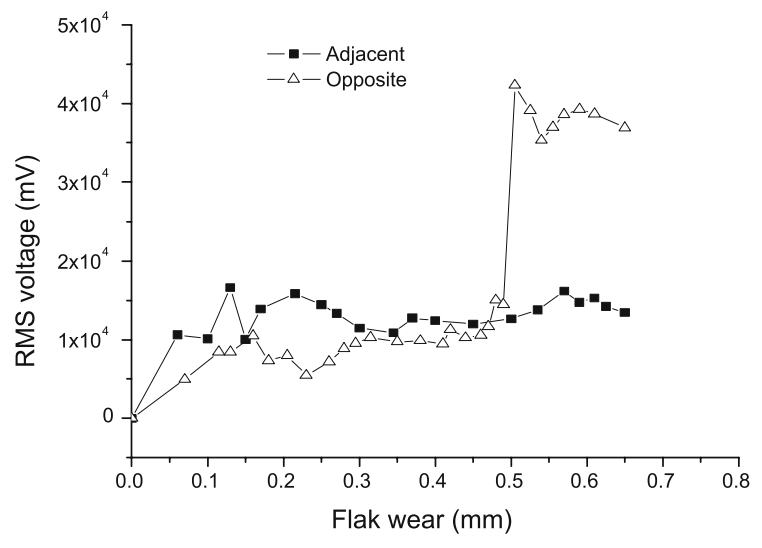

Figure 7. Evolution of RMS voltage with flank wear (2 inserts).

Some interesting observations were found from the experiments with two inserts placed opposite to each other and adjacent to each other in the cutter. Inserts placed adjacent to each other undergo wear faster, when compared with inserts placed opposite to each other. The values of RDC and RMS voltage corresponding to critical wear value for the adjacent arrangement are greater than that of opposite arrangement.

Further, the present investigation aimed at analysing the behaviour exhibited by various AE parameters, for different cutting conditions and different number of inserts in the cutter. The results presented are limited to three experiments. Though extensive experiments have been carried out using single inserts experiments, limited number of experiments has been carried out using two and three inserts.

\section{Conclusions}

This experimental investigation were carried out to find the suitability of using acoustic emission for tool condition monitoring in face milling operation. Experiments were carried out using single/two inserts (adjacent and opposite) and three inserts in the cutter for different cutting conditions.

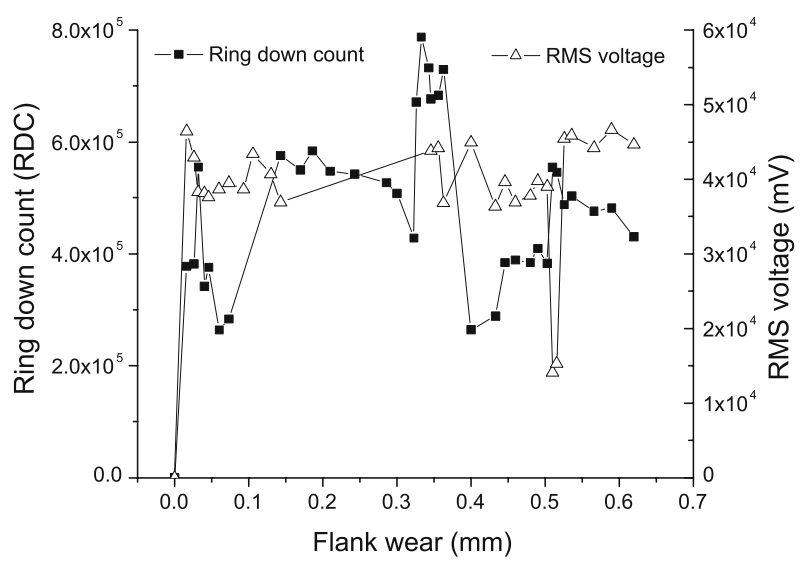

Figure 8. Evolution of ring down count (RDC) and RMS voltage with flank wear (3 inserts). 
- Ring down count (RDC) and RMS voltage can be effectively used as indicators for tool wear monitoring in face milling.

- RMS voltage is very clear in distinguishing the normal state from the abnormal state.

- Milling being an intermittent cutting process, offers lot of difficulties for tool condition monitoring.

- Thus, there is a need for more sophisticated and advanced signal processing instrumentation systems and also signal processing algorithms, which can help in using AE effectively as a sensor.

Authors gratefully acknowledge the financial support from the Department of Science and Technology (DST), Government of India and FCT, Portugal, through the individual grant SFRH/BPD/20344/2004. Authors thank the Department of Mechanical Engineering, S J College of Engineering, Mysore, India for providing facilities to conduct the tests.

\section{References}

Dimla D E Jr, Lister P M, Leighton N J 1997 Neural Network Solutions to the Tool Condition Monitoring problem in Metal Cutting_A Critical Review of Methods. Int. J. Mach. Tools Manufact. 37(9): 1219-1241

Lister P M, Barrow G 1986 Tool condition monitoring systems. Proc. of the 26th Int. Machine Tool Design and Res. Conf. pp 271-288

Pai P S, Rao P K R 1998 In-process detection of tool wear in face milling using acoustic emission. Second International Tribology Conference, Toronto, Canada, Oct 25-28 